\title{
OS DESAFIOS DA DOCÊNCIA NO MUNDO CONTEMPORÂNEO: CONSIDERAÇÕES SOBRE O ENSINO DE GEOGRAFIA E A GEOGRAFIA DA SAÚDE
}

\section{ARTIGO DE REVISÃO}

NASCIMENTO, Márcio Moreira Do ${ }^{1}$

NASCIMENTO, Márcio Moreira Do. Os desafios da docência no mundo contemporâneo: Considerações sobre o ensino de Geografia e a Geografia da Saúde. Revista Científica Multidisciplinar Núcleo do Conhecimento. Ano 05, Ed. 05, Vol. 03, pp. 66-82. Maio de 2020. ISSN: 2448-0959, Link de acesso: https://www.nucleodoconhecimento.com.br/geografia/geografia-da-saude

\section{RESUMO}

O artigo apresenta um breve histórico do surgimento da Geografia até os dias atuais e apresenta o problema da interferência da globalização na educação. Conhecer a história e seus conteúdos garante meios de trabalho para termos uma visão geral, um olhar geográfico no contexto educacional propondo repensar a prática de ensino, respondendo como os desafios da docência no mundo moderno podem afetar esta Ciência e como a Geografia da saúde pode colaborar tanto em sala quanto com os gestores locais. A metodologia utilizada neste trabalho foi a pesquisa bibliográfica. Este trabalho tenta responder qual é o desafio da Geografia no mundo contemporâneo e demonstrar que através do conhecimento teórico é que conseguimos construir o raciocínio geográfico, se utilizando da sistematização da Geografia e as contribuições, definições de Milton Santos, para assim, colaborar com à formação profissional e com a educação geográfica, discutir a temática envolvendo a Geografia da Saúde, pois esta muitas vezes não é considerada em sala de aula e possui muitas contribuições para o atual cenário mundial. É necessário aprofundar a discussão conceitual e teórica

\footnotetext{
${ }^{1}$ Mestrando em Geografia (UFMS-Aquidauana); Especialização em Gestão Escolar; Graduação em pedagogia.
} 
no contexto educacional, pois amplia a capacidade investigativa e de compreensão do mundo, relacionando a teoria com a prática para realizar a leitura do espaço, tendo condições de contribuir para a educação geográfica, processo essencial no ensino de geografia.

Palavras-chave: Educação, geografia, saúde.

\section{INTRODUÇÃO}

A palavra Geografia foi utilizada pela primeira vez por Eratóstenes (276-194 a.C.), é complexa, abrangente envolve-se com diversos assuntos, o principal deles é o estudo da Terra e dos seus habitantes e da relação existente. Os conceitos que estabeleceram a Geografia como ciência e método de pensamento filosófico, surgem na Grécia Antiga, neste período era conhecida como História Natural ou Filosofia Natural.

A Geografia demorou para se estabelecer como Ciência, somente no final do século $\mathrm{XIX}$, que teve seu reconhecimento como disciplina, surgindo neste período, a Geografia moderna, que se apresenta como Geografia Geral e Geografia Regional. A Geografia Geral dedica-se ao estudo espaço geográfico e pode ser dividida em Geografia Humana e Física. A Geografia humana se pauta em compreender a atividade humana sobre o espaço, por exemplo, as dinâmicas demográficas, espaço econômico, agrário e o crescimento urbano entre outros. Existem alguns conceitos que em conjunto ao espaço geográfico formam o pensamento geográfico, com os seguintes temas: território lugar, paisagem e região.

A Geografia física estuda o relevo, isto é a litosfera (camada externa sólida da superfície do planeta) a atmosfera (camada de gases que envolvem o planeta), a hidrosfera (parte líquida que cobrem parcialmente à Terra), a biosfera e geosfera. A Geografia Regional se interessa em estudar eventos particulares pautando pelas características específicas dos locais não se preocupando com raciocínios universais. O desenvolvimento tecnológico também afetou a Geografia, mudando assim suas 
formas e ferramentas, sejam estas no meio de trabalho prático, bem como na continuidade do ensino em qualquer nível escolar.

\section{MATERIAIS E MÉTODOS}

Desta maneira, o presente trabalho buscará responder quais os desafios da docência no mundo contemporâneo? O que afeta de forma direta o ensino de Geografia e em que a Geografia da Saúde pode ser utilizada?

Este trabalho tem como objetivo de apresentar o cenário do ensino no Brasil. Como objetivos específicos, apresenta relação entre a globalização e a educação um pequeno histórico sobre a educação no Brasil, as políticas de formação de profissionais da educação, apresentar a história, e abordar de forma rápida a Geografia em saúde, mostrar sua visão geral, sua história e as áreas de estudo.

A metodologia aqui adotada teve por base pesquisas bibliográficas, consultas a livros, revistas, manuais, tratados e em artigos publicados em "websites" da "internet".

A pesquisa tem por objetivo reunir informações e dados, que servem para explicar e discutir um determinado tema com referências teóricas já publicadas. Desta forma busca também, traçar um histórico sobre o objeto de estudo e a identificar possíveis respostas anteriormente encontradas sobre determinado tema.

Para o presente estudo, utilizou-se pesquisas relacionadas ao tema, artigos que apresentam o tema em questão, teses, dissertações além de textos, artigos e citações traduzidas.

\section{HISTÓRIA DA GEOGRAFIA}

O surgimento da Geografia acontece na Grécia antiga, com o pensamento filosófico, recebendo contribuições de Tales de Mileto, Eratóstenes, Hiparco, Aristóteles, Heródoto, Estrabão. O mapa mais antiga conhecida da Babilônia do século IX a.C. O Imago Mundi de 600 a.C. (CASTROGIOVANNI, 2007). 
Com a expansão da Grécia causada por Alexandre o Grande, e a necessidade de estudar as terras colonizadas e principalmente com as técnicas de navegação que contribuíram com o mercado comercial, e com a agricultura do período.

Hiparco desenvolveu um sistema de latitude e longitude com base na matemática babilônica empregou um sistema sexagesimal. Dividiu os meridianos em $360^{\circ} \mathrm{C}$, e cada grau subdividido em 60 (minutos), medindo a longitude utilizando eclipses determinando a diferença relativa no tempo (ALBUQUERQUE, 2011).

A Geografia mais uma vez contribui desta vez com o Império Romano com a descrição de rotas e escalas para a navegação e localização dos portos, tudo para realizar o comércio e a proteção militar de forma rápida (SILVA, 2013).

$\mathrm{Na}$ idade média os Árabes mantiveram e aprofundaram os conhecimentos gregos, possuindo uma casa de estudos o que perdurou pelo período da Renascença e durante os séculos XVI e XVII. E principalmente com as grandes navegações, já no século XVIII, a Geografia começou a ganhar destaque e a ser reconhecimento nas universidades (LYONS, 2011).

A Geografia passou pelo determinismo geográfico, pela Geografia Regional, pela revolução quantitativa e também pela geografia radical (CAMPOS, 2014)

\section{HISTÓRIA DA GEOGRAFIA NO BRASIL}

Quando o Brasil começou a ser colonizado por Portugal no século $\mathrm{XV}$, já possuía habitantes os povos indígenas, porém as tribos que não possuíam sistema de escrita ou educação escolar (SINGER, 1986).

A missão dos jesuítas foi fundada para promover a causa e os ensinamentos do catolicismo, estavam comprometidos com o ensino e a educação, o que influenciou a abertura de escolas para meninos, primeiro na Europa e após na América e Ásia (PIMENTA, 1990). 
As escolas e seminários católicos foi consequência deste envolvimento com a educação, e seus métodos de evangelização eram diferentes de um lugar para outro. E o envolvimento na sociedade no comércio e em diversas ciências na época e tinha como objetivo a cristianização da comunidade na época.

No final do século XVIII, o ministro português, Marquês de Pombal expulsou os jesuítas de Portugal realizou as reformas educacionais (ALMEIDA, 2003).

O Brasil até o século $X X$, era exclusivamente rural sua economia era baseada no setor primário não possuindo profissionais qualificados. As primeiras faculdades de direito fundadas no Brasil foram em Recife e São Paulo, em (EMER,1991).

\section{A EDUCAÇÃO NO BRASIL}

As missões jesuítas controlavam a educação por quase duzentos anos, entretanto sua atuação foi limitada pelo Marquês de Pombal. Logo após esse período, o governo brasileiro assumiu sendo administrado pelo Ministério da Educação (NOVAIS, 1995).

O sistema educacional no Brasil foi "herdado" e pensado de cima para baixo, copiando "modelos" educacionais de outros países.

A educação no Brasil é avaliada do Programa Internacional de Avaliação de Alunos (PISA), e também do IDEB agora usada pelo Ministério, que avalia o desempenho dos alunos e das escolas.

Os resultados da avaliação Pisa no Brasil é percebida de duas maneiras a primeira que quer construir um, país mais justo e solidário, verificando o que já avançamos, considerando o atual cenário de um, país, continental com grandes desigualdades sociais, e com pouco investimento em ciência e tecnologia. A segunda que compara - Brasil a países de primeiro mundo, acreditando que é através do desenvolvimento que trará a igualdade social. Algumas universidades não preparam o educador o diaa-dia de sala de aula com baixa remuneração. As escolas estão tendo dificuldades de estar acompanhando o ritmo das transformações da era pós-digital, com o currículo 
inchado, disciplinas demais para tempo de menos ausência de ensino técnico integrado a essa etapa escolar, estamos com mesmo problemas utilizando a BNCC.

A globalização perversa apresentada por Milton Santos, deixa claro que as pessoas estão perdendo direitos adquiridos, sendo marginalizadas, o mercado global cada vez mais influência as empresas a pagarem salários menores. Os governos não conseguem proteger sua população dos efeitos dessa globalização, em contrapartida, a educação é considerada um gasto, não possuindo investimento satisfatório em educação. As tecnologias e condições inadequadas de trabalho para os profissionais, que mal remunerados ampliam sua jornada de trabalho significativamente o que acaba impactando no planejamento e na qualidade de seu trabalho.

\section{POLÍTICA DE FORMAÇÃO DE PROFESSORES NO BRASIL}

No Brasil os professores são cerca de dois milhões, $80 \%$ dos quais no setor de escolas públicas, atendem a 51 milhões de alunos em escolas de educação básica, portanto, não surpreende que a formação dessa categoria profissional influencia o crescimento do ensino superior em nosso, país. Se analisarmos o Censo do Ensino Superior em 2011, 26\% foi dedicado à formação de profissionais da educação básica. As faculdades de professores são as segundas escolas de ensino superior mais comum no Brasil, totalizando 1801 - nas escolas de administração de empresas 2279, e a maioria entre as que oferecem credenciamento de professores.

Os cursos de formação de profissionais da educação no Brasil seguem em termos gerais as necessidades educacionais para a população, com atraso para introduzir a escolaridade obrigatória demorou para ser alcançada. Em 2006, a escolaridade é ampliada de 8 para 9 anos com a Emenda Constitucional 59/2009, aumentou 4 a 17 anos, o que corresponde da pré-escola ao final do ensino médio. A educação passa a ser oferecida para crianças recém-nascidas, conforme determinado pela Constituição Federal de 1988, também tornou um dever público oferecer cuidados de primeira infância para crianças de até três anos. Embora a taxa de natalidade tenha diminuído drasticamente no Brasil e ficou abaixo da taxa de reposição, a necessidade 
de ampliar as oportunidades de escolarização é grande, pois é a forma dominante pela qual as crianças e os adolescentes são educadas na atual sociedade.

A educação básica certamente amplia postos trabalho para professores de proporções sem precedentes. Há, no entanto, dinâmicas dentro do sistema educacional e no mercado que expandem e retraem a oferta e demanda por cursos que educam os profissionais docentes.

A Lei de Diretrizes e Bases da Educação Nacional de 1996 (Brasil, 1996) tem servido como uma estrutura regulatória decisiva para a formação de professores nas últimas décadas. A lei determina que os professores devem ser formados ao nível superior, e considera a educação a distância como uma forma de educação formal o que favorece a expansão da formação necessária de professores.

Embora o credenciamento de professores em cursos de ensino superior esteja se tornando a norma em todo o Brasil, a qualidade da educação básica não pode ser melhorada simplesmente pelo grau de oferta aos professores. Existem problemas que surgem da expansão dos cursos, que também estão relacionados à sua qualidade (BARRETO, 2012).

\section{GLOBALIZAÇÃO E EDUCAÇÃO}

A globalização é hoje um fenômeno inegável, afetando profundamente os sistemas de todos os estados o termo surgiu da percepção de que o mundo se encontra em um processo, através do qual se tornará uma espécie de "estado global" ou, pelo menos, um único sistema econômico, sociopolítico e cultural. Portanto, as implicações desse fenômeno para o campo da educação são sérias e convincentes. O século XX é o período mais dinâmico e denso em desenvolvimento de fenômenos complexos e contraditórios que tiveram importantes consequências e efeitos no plano econômico, social, político e militar. O século XX é considerado o século dos extremos, durante o qual a humanidade alcançou os desenvolvimentos mais espetaculares (conseguindo comprimir o tempo e encurtar as distâncias) possuindo elevado o nível de desenvolvimento cultural e econômico. É também o século em que centenas de 
milhares de pessoas foram vítimas de fenômenos globais: a guerra, "revoluções nos campos econômicos, político, científico e técnico" e a intolerância ideológica da pobreza crônica.

Hoje, globalização significa "mundo em movimento". A globalização é um conceito abstrato, porque não se refere a um objeto "concreto" enfatizado por seu tamanho natural, facilmente identificável por unidades de medida estabelecidas. Podemos dizer que não há indicador ou índice alcançado estatisticamente através de cálculos matemáticos que possam quantificar a extensão desse fenômeno. Devido a esse fato, esse fenômeno não é fácil de definir. A globalização é um evento contemporâneo. Não tem uma causa específica, porque não há causalidade na forma singular, há apenas causalidades (DELORS, 2010).

O termo "globalização" foi utilizado no final dos anos 60 pelo especialista canadense na teoria do professor Marshall McLuhan, Universidade de Toronto e especialista americano em "Questões do comunismo", Zbigniew Brzezinski, Colúmbia Universidade. McLuhan extrapolou as lições da Guerra do Vietnã e lançou a frase "aldeia global".

Um mundo globalizado é aquele em que os eventos políticos, econômicos, culturais e sociais estão interligados. Brailen (2011), afirma que "até hoje não havia sociedade humana", significando que só hoje falamos de formas de associação que se espalham pelo mundo. A globalização como crescente interdependência global. Nesse sentido, a globalização é uma espécie de somatório do espaço mundial.

Globalização como expansão da dominação e dependência. A dominação e a dependência estendida às relações internacionais e transnacionais aplicam-se particularmente às econômicas, políticas e culturais (conceituadas como "imperialismo cultural"). É importante que este a expansão das relações globais não seja constantemente variável dependendo das conexões entre as relações radial e lateral. Globalização como homogeneização do mundo. 
Apesar do aumento pronunciado da interdependência econômica e cultural, o sistema global é caracterizado pela desigualdade e dividido em um "mosaico" de estados, cujos interesses podem ser comuns, mas também divergentes.

Segundo Milton Santos (2000), em sua obra Por uma outra globalização o mundo é dividido em "globalização como fábula" (um mercado avassalador global para o consumo), "globalização como perversidade" ("fábrica de perversidades desemprego, marginalização, novas enfermidades, consumo fonte de felicidade") e "globalização como possibilidade" ("uma outra globalização"). Exemplo desta globalização são as empresas multinacionais atuando em países de terceiro mundo que exploram os trabalhadores, pagando a fração de segundo, para não mostrar o real valor pago pela mão de obra, este é o exemplo de globalização perversa, empresas só pensam no lucro, não possuindo compromisso social e nenhuma preocupação com a comunidade local.

\section{GEOGRAFIA DA SAÚDE}

A Geografia da saúde é uma subdisciplina da Geografia humana, que trata da interação entre as pessoas e o meio ambiente. A Geografia da saúde vê a saúde de uma perspectiva holística que abrange a sociedade e o espaço e conceitua o papel do lugar, localização e Geografia na saúde, bem-estar e doença (SANTIAGO, 2012)

Embora a Geografia da saúde esteja estreitamente alinhada com a epidemiologia, sua ênfase primária distinta é nas relações e padrões espaciais. Enquanto a epidemiologia se baseia no modelo biomédico e se concentra na biologia da doença, a Geografia da saúde procura explorar os contextos sociais, culturais e políticos da saúde dentro de um quadro de organização espacial (DUTRA, 2007)

Tradicionalmente, o estudo da Geografia da saúde possui dois caminhos distintos: os padrões, as causas e a disseminação de doenças, planejamento, e a prestação de serviços de saúde. A pesquisa nessas áreas interligadas apoia o desenvolvimento de políticas. Por exemplo, a epidemiologia da doença está em parte relacionada à Geografia da prestação de serviços de saúde (GIL, 2002). 


\section{VISÃO GERAL}

O estudo da Geografia da saúde sofre influência da Geografia médica que posiciona diante da Geografia social, devido a uma mudança para um modelo social na área da saúde, em vez de um modelo médico. Isto defende a redefinição da saúde e dos cuidados de saúde, desde a prevenção e tratamento da doença, até à promoção do bem-estar, em geral. Sob este modelo, algumas doenças prévias (Doença mental) são reconhecidas como distúrbios de comportamento apenas, e outras categorias de medicina (por exemplo, medicina complementar ou alternativa e medicina tradicional) são estudadas pelos pesquisadores da medicina às vezes com a ajuda da saúde geógrafa sem educação médica (MINAYO, 2010)

Essa mudança altera a definição de cuidado, não mais a limitando a espaços como hospitais ou consultórios médicos. Além disso, o modelo social dá prioridade aos encontros íntimos realizados nos espaços não tradicionais da medicina e da saúde, bem como aos indivíduos como consumidores de saúde (CLAVAL, 2002)

Essa abordagem metodológica alternativa significa que a Geografia médica é ampliada para incorporar filosofias como a economia política marxista, o estruturalismo, o interacionismo social, o humanismo, o feminismo e a teoria Queer (RAMOS, 2014).

\section{HISTÓRIA}

A relação entre espaço e saúde remonta a Hipócrates, que afirmou que "ares, águas, lugares" todos desempenharam papéis significativos, impactando a saúde humana e a história. Uma peça clássica de pesquisa em Geografia da saúde foi feita em 1854, quando um surto de cólera atingiu um bairro em Londres. O número de mortos soava 24 horas e as pessoas temiam estar sendo infectadas por vapores vindos do solo John Snow pensou se conseguisse localizar a fonte da doença ela poderia ser contida. Ele desenhou mapas demonstrando as casas de pessoas que morreram de cólera, os locais e bombas de água. E descobriu que a água de um poço poderia ser o problema e a bomba de água pública na Broad Street, era responsável para a maioria das 
vítimas. Ele concluiu que a água infectada da bomba foi a culpada. Ele orientou as autoridades a retirar alça da bomba, para que não conseguissem mais retirar água do poço. Como resultado, o número de novos casos de cólera diminuiu (PENA, 2016).

\section{1. ÁREAS DE ESTUDO}

A Geografia da saúde é considerada dividida em dois elementos distintos. O primeiro deles é focado em Geografias de doenças, envolvendo pesquisas descritivas quantificando frequências e distribuições de doenças, e pesquisas analíticas preocupadas em descobrir quais características tornam um indivíduo ou população suscetível a doença. Isso requer uma compreensão da epidemiologia. O outro é a Geografia dos cuidados, para melhor adequação e principalmente com a localização das instalações, a acessibilidade e a utilização. Isso requer o uso de análise espacial e muitas vezes toma emprestado da economia comportamental (FILIZOLA, 2009).

\section{GEOGRAFIAS DE DOENÇAS E PROBLEMAS DE SAÚDE}

Percebendo riscos à saúde, desde desastres naturais até violência interpessoal. Estresse e outros perigos potenciais (ANDRADE, 2009).

Geografia da prestação de cuidados de saúde - Embora a saúde seja um bem público, ela não é igual para todos os indivíduos. A demanda por serviços públicos está aumentando continuamente. As pessoas precisam de conhecimento avançado e da mais recente tecnologia de previsão, que a Geografia da saúde oferece. O exemplo mais recente dessa tecnologia é a telemedicina. Muitas pessoas nos Estados Unidos não conseguem ter acesso a cuidados de saúde adequados devido à desigualdade no seguro de saúde e aos meios para pagar cuidados médicos.

Mobilidade e Rastreamento de Doenças - Com o advento da tecnologia móvel e sua disseminação, agora é possível rastrear a mobilidade individual. Ao correlacionar o movimento dos indivíduos através do rastreamento dos dispositivos usando torres de acesso ou outros sistemas de rastreamento, agora é possível determinar e até mesmo controlar a disseminação de doenças. Embora as leis de privacidade questionam a 
legalidade do rastreamento de indivíduos, os provedores comerciais de serviços móveis estão usando técnicas secretas ou obtendo isenções do governo para permitir a permissão para rastrear pessoas.

\section{RESULTADOS E DISCUSSÕES}

Tanto os resultados como os desafios devem ser o eixo do conhecimento e das reflexões. Portanto, precisamos expor breve história da Geografia algumas tendências e contribuições, com base em algumas conclusões que o professor Araya (2008) forneceu com um processo de pesquisa que realizou no contexto latino-americano e socializou em "Geoforo Iberoamericano".

Pensar e reconhecer a Geografia como uma ciência que estuda os espaços geográficos mais próximos e mais distantes, deve entender a inter-relação do homem do espaço em que vive entendendo a particularidade para que assim possa aprofundar os estudos da complexidade, sócio territorial. Este é um desafio e uma tarefa interessante para o processo de ensino de Geografia, com isso, a escola deve promover a capacidade que as pessoas têm de reconhecer, entender e valorizar o espaço geográfico próximo e imediato em que vivem.

Essa nova forma de pensar a Geografia, em que os professores teriam o papel condutor para esta observação, esclarecimento e compreensão de realidades sócio territorial diverso, e riquíssima e traz elementos importantes para poder descobrir a dinâmica e a complexidade da Geografia. É importante esse olhar mais amplo para redesenhar não apenas o currículo, mas também a didática e o processo de ensinoaprendizagem na escola em relação ao verdadeiro núcleo da Geografia. No entanto, a educação em Geografia não está relacionada apenas aos processos de observação e leitura de diferentes realidades e cenários da escola. Ele tem que lidar com a necessidade de aprofundar sua evolução em direção a novas expectativas e horizontes de conhecimento espacial.

A Geografia como ciência social tem um alvo claro o espaço geográfico e suas complexidades. Seu processo de aprendizagem deve motivar os alunos a conhecer, 
compreender, ler e assimilar o espaço, evitando a memorização isolada dos elementos espaciais que o compõem. É aconselhável ler didática da Geografia com base nos debates e reflexões sobre o seu processo de ensino e sobre os elementos cognitivos, emocionais e compreensíveis do contexto espacial.

Esses elementos são úteis não apenas para conhecer e reconhecer o conceito de espaço, mas também para construir e desenvolver uma variedade de formas e possibilidades de interação com o espaço. Além disso, esses elementos têm que se considerar para o progresso no estudo e na compreensão de redes espaciais que tenham um certo ritmo, algumas mudanças e flutuações, e que estimulem os seres humanos a reconhecer e assimilar suas transformações.

É imperativo considerar as diferentes concepções e significados que o espaço tem para ser entendido sob as diversas e complexas escalas que o compõem. Esta tarefa deve ter apoio do ensino do espaço em relação aos contextos territoriais e utilizando as experiências e conhecimentos prévios que os alunos da escola têm.

Segundo Fernandez (2007) com base nessas experiências anteriores, é possível obter mudanças na concepção que as pessoas têm da Geografia e, em geral, na concepção de diferentes lugares. Este fato traz alternativas para observar através de um espaço uma variedade de interpretações e alternativas para abordar os lugares e a interação homem-território, questões que lidam com as atividades diárias das pessoas. Além disso, a oportunidade de tentar outras abordagens da realidade para compreender e adotar uma posição frente às situações problemáticas que a nossa sociedade enfrenta, e para dar uma nova direção ao significado do processo de ensino da Geografia. (FERNANDEZ, 2007).

É necessário citar Souto (1999) que afirma: mudar a concepção de Geografia das pessoas implica defini-la como ciência que não é apenas responsável pelos conceitos inerentes ao assunto, mas também por diferentes contextos sociais e canais de comunicação com nossos alunos. Outro desafio para a didática da Geografia é a necessidade de se aprofundar na reflexão do como e do porquê de ensinar este assunto, tomando como ponto de partida o complexo estudo do espaço e do território, 
num grande esforço para formar cidadãos críticos que entendam o seu contexto espacial, e capazes de desenvolver propostas tendentes a gerir e resolver os problemas espaciais que têm que enfrentar, no dia a dia, e nos locais onde vivem.

\section{CONCLUSÃO}

Talvez o maior desafio da Geografia na escola, seja livrar-se de conteúdos isolados e fragmentos e comprometer-se a construir redes espaciais inter-relacionadas capazes de reconhecer e compreender um sistema complexo e interativo de objetos e ações que devem ser estudadas no ensino fundamental ao ensino médio. Tendo em mente os estágios cognitivos dos alunos, a maturidade intelectual e os contextos socioculturais.

Existem algumas experiências inovadoras no processo de ensino de Geografia, e com a colaboração da Geografia da Saúde auxiliando o gerenciamento público para melhor efetivar os recursos públicos oferecendo um atendimento realmente universal obedecendo aos princípios do SUS, pois os recursos deverão ser melhor aplicados para atender a população. Portanto, este artigo se torna um convite para incluir tendências, experiências e resultados que enriquecem o processo de ensino de Geografia, tendo em mente nossos próprios contextos, observações próximas e imediatas, e envolvendo o grande grupo de professores interessados nesta questão.

\section{REFERÊNCIAS}

ALBUQUERQUE, Maria Adailza Martins de. Século de prática de ensino de Geografia permanências e mudanças. In: REGO, Nelson; CASTROGIOVANNI, Antônio Carlos, KAERCHER, Nestor André (orgs). Geografia: práticas pedagógicas para o ensino médio. Volume 2, Porto Alegre: Penso, 2011.

ALMEIDA, A. C. L. Notas sobre a Reforma Pombalina dos estudos menores no Brasil. In: MAGALDI, A. M. (org.). Educação no Brasil: Historia, Cultura e Política. Bragança Paulista, SP: EDUSF, 2003.

ALMEIDA, F.D.M. Competências na Constituição de 1988. São Paulo: Atlas, 1991. 
ANDRADE, Aparecido Ribeiro. Reflexões sobre o pensamento geográfico e a busca de uma Metodologia de trabalho na percepção da Geografia ambiental. Rev. Geografar Curitiba, v.4, n.2, p.29-46, jul./dez. 2009

ARAYA, F. (2008). Balance y tendencia de la geografía escolar latinoamericana.

BRAILEN, T. (2011) „Noua economie. Sfârsitul certitudinilor”, Ed. Institutul European, lași.

BARRETTO, ESS Universidade e educação básica; Lugares e Sentidos da Formação de Professores. Em: Cunha, C.; Sousa, JV; Silva, MA (Orgs.). Universidade e educação básica: objetivos e articulações possíveis. Brasília: Faculdade de Educação, UnB; Liber Livro, 2012. p. 179-197.

BRASIL. Lei n. 9.394, de 20 de dezembro de 1996. estabelece como diretrizes e bases da educação nacional. Diário Oficial da União, Brasília, DF: Presidência da República, 23 dez. 1996.

CAVALCANTI, Lana de Souza. Geografia e pratica de ensino. Goiânia: alternativa, 2002.

DE CAMPOS, Rui Ribeiro. Breve histórico do pensamento geográfico brasileiro nos séculos XIX e XX. Paco Editorial, 2014.

CASTROGIOVANNI, Antônio Carlos. Para entender a necessidade de práticas prazerosas no ensino de Geografia na pós-modernidade. In: REGO, Nelson; CASTROGIOVANNI, Antônio Carlos, KAERCHER, Nestor André (orgs). Geografia: práticas pedagógicas para o ensino médio. Porto Alegre: Artmed, 2007.

CHASIN, J. A miséria brasileira: 1964-1994 - do Golpe Militar à crise social. Santo André, SP: Ad.Hominem, 2000.

CLAVAL, Paul. A revolução pós-funcionalista e as concepções atuais da Geografia. In: MENDONÇA, F.; KOZEL, S. (orgs.). Elementos de Epistemologia da Geografia Contemporânea. Curitiba: Editora da UFPR, 2002. p. 11-46. 
DELORS, J., (2010) Comoara lăuntrică, Raportul către UNESCO al Comisiei internaţionale pentru Educaţie în secolul XXI, laşi, Editura Polirom, p.30.

DUTRA, Denecir de Almeida. A Geografia da Saúde como uma escola geográfica. Rev. Elet. Geografar, Curitiba, v. 2, Resumos do VI Seminário Interno de PósGraduação em Geografia, p. 18-18. Junho/2007.

EMER, I. O. Desenvolvimento Histórico do Oeste do Paraná e a Construção da Escola. Dissertação de Mestrado. Rio de Janeiro: FGV. 1991.

FÁVERO, O. A Educação nas Constituintes Brasileiras: 1823-1988. Campinas, SP: Autores Associados, 1996.

FERNÁNDEZ, M. V., Gurevich, R. (2007). Geografía. Nuevos temas, nuevas preguntas. Buenos Aires: Editorial Biblos.

FILIZOLA, Roberto. Didática da Geografia: proposições metodológicas e conteúdos entrelaçados com a avaliação. Curitiba: Base Editorial, 2009.

FRANÇA, S. J. L. O Método Pedagógico dos Jesuítas - 0 Ratio Studiorum. Introdução e Tradução. Rio de Janeiro: Editora e Livraria Agir, 1952.

GERMANO, J. W. Estado Militar e Educação no Brasil. 2 ed. São Paulo: Cortez, 1994.

GHIRALDELLI JUNIOR, P. História da Educação. 2 ed. São Paulo: Cortez, 2001.

GIL, Antônio Carlos. Como elaborar projetos de pesquisa. 5. ed. São Paulo: Atlas, 2002.

GONÇALVES, R. A. (org). Luzes e Sombras sobre a Colônia - Educação e Casamento na São Paulo do século XVIII. ํㅡ 3. São Paulo: Humanitas Publicações FFLCH/USP-Departamento de História, 1998. 
LACOSTE, Yves. Geografia: isso serve, em primeiro lugar, para fazer a guerra. Campinas, SP: Papirus, 1988.

MACHADO, L. R. S. Educação e divisão social do trabalho: contribuição para o estudo do ensino técnico industrial brasileiro. São Paulo: Autores Associados Cortez, 1982.

MARX, K. Prefácio à Contribuição à crítica da economia política. São Paulo: Martins Fontes, 1983.

MINAYO, Maria Cecilia. O desafio do conhecimento: Pesquisa Qualitativa em Saúde. 12. ed. São Paulo: Hucitec-Abrasco, 2010

NADAI, E. História do Brasil: da Colônia a República. 13 ed. São Paulo: Saraiva, 1990

NOGUEIRA, F. M. G. Ajuda externa para a educação brasileira: da USAID ao Banco Mundial. Cascavel, Pr: Edunioeste, 1999.

NOVAIS, F. A. O Brasil nos quadros do antigo sistema colonial. In: DIAS, M. N. Brasil em perspectiva. 20 ed. Rio de Janeiro: Ed. Bertrand Brasil, 1995.

OLIVEIRA, Ariovaldo Umbelino de. Para onde vai o ensino de Geografia? (org.). 9. ed.- São Paulo: contexto, 2005

OLIVEIRA, Marlene Macário de. A Geografia Escolar: Reflexões sobre o Processo Didático Pedagógico do ensino 1998.

PESSOA, Rodrigo Bezerra. Um olhar sobre a trajetória da Geografia escolar no Brasil e a visão dos alunos de ensino médio sobre a Geografia atual. 2007. Dissertação de (Mestrado em Geografia), Universidade Federal da Paraíba, 2007.

PARANÁ. Decreto 7.734, de 07 de outubro de 1983. Denomina Colégio Polivalente Pedro Boaretto Neto, ensino de 20 grau. Curitiba, Pr: 1983. 
PENA, Rodolfo F. Alves. Espaço geográfico. Portal Brasil Escola, 2016.

PIMENTA, S. G. Revendo o ensino de $2^{\circ}$ grau: propondo a formação de professores. São Paulo: Cortez, 1990.

QUELUZ, Ana Gracinda. 0 trabalho docente. Teoria e prática. São Paulo: Editora Guazzelli, 1999.

RAMOS, Rafaela Rodrigues. O Espaço na Investigação em Saúde: uma Perspectiva Geográfica? Londrina: Rev. Geografia, v. 23, n.1, p. 173 - 189, jan/jun, 2014.

ROMANELLI, O. O. História da Educação no Brasil (1930/1973). Petrópolis, RJ: Vozes, 1983.

SANTIAGO, Emerson. Geografia da Saúde. Artigo colaboração Info Escola navegando e aprendendo, 2012.

SCHELBAUER, A. R. Idéias que não se realizam: o debate sobre a educação do povo no Brasil de 1870 a 1914. Maringá, Pr: EDUEM, 1998.

SHIROMA, E. O. Política Educacional. Rio de Janeiro: DP\&A, 2000.

SINGER, P. Interpretação do Brasil: Uma Experiência Histórica de Desenvolvimento. In: FAUSTO, B. O Brasil Republicano. 3 ed. Tomo III. Difel , São Paulo, 1986.

SILVA, Bruno dos Santos. Estrabão e as Províncias da Gália e da Ibéria: um estudo sobre A Geografia e o Império Romano. 2013. Tese de Doutorado. Universidade de São Paulo.

SOUSA, Manoel Fernandes de Sousa, A aula. Geografares, Vitória, oำ 2, jun. 2001. SOUTO, X. (1999). Didáctica de la Geografía. Barcelona: Ediciones del Serbal.

SPERANÇA, A. A. Cascavel: a história. Curitiba, Pr: Lagarto, 1992. 
Enviado: Abril, 2020.

Aprovado: Maio, 2020. 